\title{
Analytical representations of the Residence Time Distribution (RTD) associated with Hyporheic Exchange beneath Dune-like bedforms at different sediment bed depths
}

\author{
Ahmed Monofy $^{1}$, Fulvio Boano ${ }^{1}$, and Stanley Grant ${ }^{2}$ \\ ${ }^{1}$ Politecnico di Torino \\ ${ }^{2}$ Virginia Tech
}

June 23, 2021

\begin{abstract}
The hyporheic exchange below dune-shaped bedforms has a great impact on the stream environment. One of the most important properties of the hyporheic zone is the residence time distribution (RTD) of flow paths in the sediment domain. Here we evaluate the influence of an impervious layer, at a dimensionless sediment depth of $d_{b}^{*}=\frac{2 \pi d_{b}}{\lambda}$ where $\lambda$ is the dune wavelength, on the form of the hyporheic exchange RTD. Empirical RTDs were generated, over a range of $d_{b}^{*}$ values, from numerical particle tracking experiments in which 10000 particles sinusoidally distributed over a flatbed domain were released. These empirical RTDs are best represented by the Gamma, Log-Normal and Fréchet distributions over normalized bed depth of $0<=d_{b}^{*} \leq 1.2,1.2<d_{b}^{*} \leq 3.1$, and $d_{b}^{*}>3.1$, respectively. The depth dependence of the analytical distribution parameters is also presented, together with a set of regression formulae to predict these parameters based on $d_{b}^{*}$ with a high degree of accuracy $\left(R^{2}>99.8 \%\right)$. These results contribute to our understanding of the physical and mixing processes underpinning hyporheic exchange in streams and allow for a quick evaluation of its likely impact on nutrient and contaminant processing (e.g., based on the magnitude of the Damköhler number).
\end{abstract}

Keywords: Dunes, bedforms, residence times distribution, sediment depth effect, Hyporheic residence times, analytical representation, two parametric distributions, Damköhler Number.

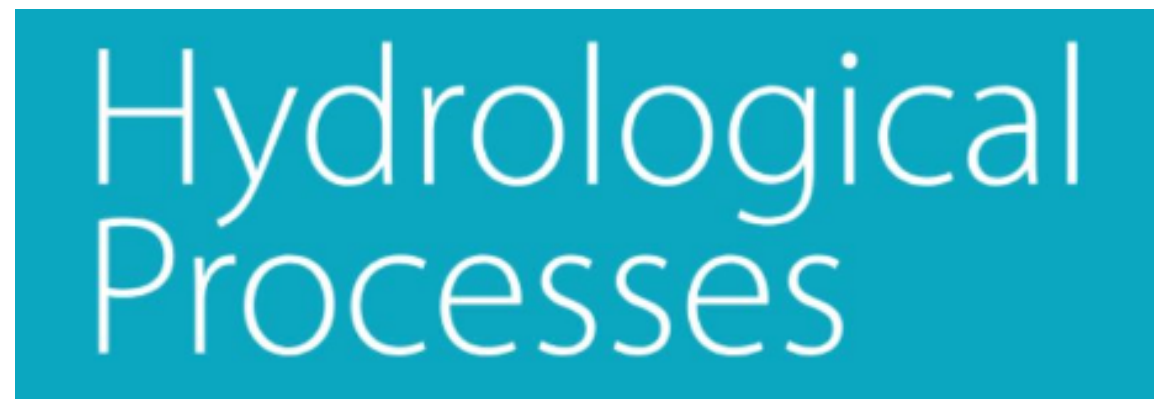

\section{Analytical representations of the Residence Time Distribution (RTD) associated with Hy- porheic Exchange beneath Dune-like bedforms at different sediment bed depths}

Ahmed Monofy ${ }^{1}$, Fulvio Boano ${ }^{1}$, and Stanley B. Grant ${ }^{2}$

${ }^{1}$ Department of Environment, Land and Infrastructure Engineering, Politecnico di Torino, Torino 10129, Italy

2 Occoquan Watershed Monitoring Laboratory, The Charles E. Via Jr. Department of Civil and Environmental Engineering, Virginia Tech, 9408 Prince William Street, Manassas VA 20110, USA 
Corresponding Author: Ahmed Monofy (ahmed.monofy@polito.it)

\begin{abstract}
The hyporheic exchange below dune-shaped bedforms has a great impact on the stream environment. One of the most important properties of the hyporheic zone is the residence time distribution (RTD) of flow paths in the sediment domain. Here we evaluate the influence of an impervious layer, at a dimensionless sediment depth of $d_{b}^{*}=\frac{2 \pi d_{b}}{\lambda}$ where $\lambda$ is the dune wavelength, on the form of the hyporheic exchange RTD. Empirical RTDs were generated, over a range of $d_{b}^{*}$ values, from numerical particle tracking experiments in which 10000 particles sinusoidally distributed over a flatbed domain were released. These empirical RTDs are best represented by the Gamma, Log-Normal and Fréchet distributions over normalized bed depth of $0<=d_{b}^{*} \leq 1.2,1.2<d_{b}^{*} \leq 3.1$, and $d_{b}^{*}>3.1$, respectively. The depth dependence of the analytical distribution parameters is also presented, together with a set of regression formulae to predict these parameters based on $d_{b}^{*}$ with a high degree of accuracy $\left(R^{2}>99.8 \%\right)$. These results contribute to our understanding of the physical and mixing processes underpinning hyporheic exchange in streams and allow for a quick evaluation of its likely impact on nutrient and contaminant processing (e.g., based on the magnitude of the Damköhler number).
\end{abstract}

Keywords: Dunes, bedforms, residence times distribution, sediment depth effect, Hyporheic residence times, analytical representation, two parametric distributions, Damköhler Number.

\title{
1. INTRODUCTION
}

The hyporheic zone is defined as the sediment immediately beneath and adjacent to streams, rivers, and riverine estuaries where surface water and groundwater interact. It is a hot spot for physical, biological and biogeochemical processes that control pollutant removal (Beaulieu et al., 2011; Grant et al., 2014), stream nitrogen cycling (Galloway et al., 2019), particle transport and mobilization (Stewardson et al., 2016), pathogen sequestration and mobilization (Grant et al., 2011), heat budgets (Sawyer et al., 2012; White et al., 1987), oxygen consumption (Tonina et al., 2015), habitat quality (Baxter \& Hauer, 2000; Wu, 2000) and stream health generally (Feminella \& Walsh, 2005).

Experimental and modeling studies support the conclusion that small bedforms, such as ripples and dunes, play an outsized role in the mixing of water across the sediment-water interface and through the hyporheic zone (Gomez-Velez et al., 2015). A key characteristic of the exchange process is the distribution of travel times over which water parcels cycle from the stream, through the hyporheic zone and back; i.e., the hyporheic exchange residence times distribution (RTD). RTDs and their statistical moments are key controls on hyporheic metabolism in the streambed (Gomez et al., 2012; Harvey \& Gooseff, 2015). For instance, the Damköhler number, a dimensionless number that compares the median hyporheic residence time and the characteristic biogeochemical reaction time, is a key predictor of nitrogen removal in streams by denitrification (Azizian et al., 2015; Grant et al., 2018; Zarnetske et al., 2012), and the emission of the potent greenhouse gas nitrous oxide $\left(\mathrm{N}_{2} \mathrm{O}\right)$ (Marzadri et al., 2014; Marzadri et al., 2017). Gomez-Velez et al. (2015) included the Damköhler Number in their analysis of N-cycling in the Mississippi River Basin.

Recently, Grant et al. (2020) unified two different descriptions for the unsteady transport of mass through the hyporheic zone by exchange across bedforms, namely, an advective pumping model (introduced by Elliott and Brooks (1997)) and a one-dimensional dispersion model, for which the dispersion coefficient decays exponentially with depth. In both cases, key water quality end points (e.g., the time evolution of mass concentration in the water column and interstitial fluids of the sediment bed, as well as mass flux across the sediment-water interface) can be obtained by convolving the time history of solute mass in the water column with either an RTD (advective model) or Green's Function (dispersion model) that describes transport and mixing in the streambed.

Many studies have been performed to investigate the RTD of water undergoing hyporheic exchange through ripples and dunes. Boano et al. (2007) utilized the continuous random waking theory (CTRW) to represent the RTDs in an infinite sediment bed. In such systems, and in the absence of an imposed groundwater flow, 
hyporheic exchange across dunes results in a strongly positively skewed (or "heavy tailed") RTD, indicating that most water parcels transit through the hyporheic zone relatively quickly, while a minority of water parcels linger for a very long time. Horizontal groundwater flow induced by longitudinal pressure gradients (so-called underflow) can reduce the RTD's positive skew and heavy tail (Bottacin-Busolin \& Marion, 2010). Likewise, experimental (e.g., Fox et al., 2014) and modeling (Azizian et al., 2017) studies indicate that vertical groundwater flow (in either gaining or losing configurations) can reduce hyporheic exchange flux and residence times in the hyporheic zone, and thereby diminish key ecological functions (such as respiration and nitrogen cycling) in streambed sediments (Gomez-Velez et al., 2014). Tonina et al. (2016) also demonstrated that sediment heterogeneity decreases the mean, increases the median, and increases the positive skew of the RTD.

Impermeable layers that limit the depth of hyporheic exchange also alter the hyporheic zone's RTD (e.g., Morén et al., 2017). Although a finite streambed depth has been considered in previous studies (Packman et al., 2000a), a systematic assessment of alluvium depth on RTDs in the hyporheic zone of dune-covered streambeds has not yet been evaluated. The aim of this work is to address this knowledge gap by identifying appropriate analytical representations of the hyporheic zone RTD for various streambed depths. The widely deployed Transient Storage model (TSM) (Bencala, 1983) implemented in the USGS OTIS package (Runkel, 1998), for example, assumes that the hyporheic zone RTD can be represented by (Harvey \& Gooseff, 2015) an exponential distribution (EXP). Although the use of an EXP distribution for the hyporheic zone RTD has been questioned (Knapp \& Kelleher, 2020), Zaramella et al. (2003) claimed that it is a reasonable approximation for shallow beds. Over the years, other analytical distributions have been suggested for the hyporheic zone RTD, including the Gamma (GAM) (Kirchner et al., 2000), Log-Normal (LN) (Cardenas et al., 2008; Wörman et al., 2002), and Fréchet (FR) (Grant et al., 2020) distributions. In this study we systematically evaluate the sediment depth ranges under which these four distributions (EXP, GAM, LN, and FR) apply, and develop a set of regression formulae for the distribution parameters that are likely to be useful in practice.

\section{METHODS}

Candidate RTDs were evaluated for different streambed depths in three steps. First, a particle tracking technique was used to generate empirical RTDs associated with bedform pumping through a hyporheic zone of various depths. Second, each of the four candidate analytical distributions (EXP, GAM, LN, and FR) were fit to the empirical RTDs, and parameter sets inferred. Finally, for each condition used to generate the empirical RTDs the four candidate analytical distributions were ranked relative to goodness of fit. Details for these three steps are described next.

\subsection{Numerical Generation of the Empirical RTDs}

To mimic the advective flow field associated with hyporheic exchange through stationary bedforms we adopted the analytical two-dimensional laminar flow model published by Packman et al. (2000), which is based on earlier analytical solutions of hyporheic exchange through streambeds by Elliott and Brooks (1997) and Vaux (1968). These models posit a sinusoidal pressure variation over the sediment-water interface (mimicking the static and dynamic pressure variations that develop on the surface of streambeds in a turbulent overlying flow (Cardenas et al., 2008), isotropic and homogeneous hydraulic conductivity, constant sediment porosity and fluid density, a so-called "Toth domain" for the upper boundary (Frei et al., 2019; Tóth, 1962), and an impermeable lower boundary at depth $d_{b}$ below the surface:

$$
\begin{aligned}
& u^{*}=-\cos \left(x^{*}\right)\left[\tanh \left(\mathrm{db}^{*}\right) \sinh \left(y^{*}\right)+\cosh \left(y^{*}\right)\right], \text { (1) } \\
& v^{*}=-\sin \left(x^{*}\right)\left[\tanh \left(\mathrm{db}^{*}\right) \cosh \left(y^{*}\right)+\sinh \left(y^{*}\right)\right], \text { (2) } \\
& h_{m}=0.28 \frac{U^{2}}{2 g}\{
\end{aligned}
$$




$$
\begin{aligned}
& \left(\frac{\frac{H}{d}}{0.34}\right)^{\frac{3}{8}} \quad \frac{H}{d} \leq 0.34 \\
& \left(\frac{\frac{H}{d}}{0.34}\right)^{\frac{3}{2}} \quad \frac{H}{d} \geq 0.34 \\
& u_{m}=k K_{c} h_{m} \tan h\left(\mathrm{db}^{*}\right) \quad(4) \\
& u^{*}=\frac{u}{u_{m}},(5) \\
& v^{*}=\frac{v}{u_{m}},(6) \\
& k=\frac{2 \pi}{\lambda},(7) \\
& x^{*}=k X,(8) \\
& y^{*}=k Y,(9) \\
& d_{b}^{*}=k d_{b},(10) \\
& t^{*}=\frac{k u_{m} t}{},(11)
\end{aligned}
$$

here, $u$ and $v$ are the horizontal and vertical Darcy fluxes, respectively, $H$ is the bedform height, $d$ is the stream depth, $K_{c}$ is the hydraulic conductivity, $u_{m}$ is the maximum Darcy flux at the bed surface, $X$ and $Y$ are the horizontal and vertical coordinates, $d_{b}^{*}$ is the relative sediment depth, $\lambda$ is the bedform wavelength, and $k$ is the wavenumber of the bedforms. The vertical coordinate, $Y$, is centred at the SWI $(Y=0)$ and oriented upward; i.e., depth into the bed corresponds to negative values of $Y$. The range of $d_{b}^{*}$ was chosen between 0.1 and20 (Supporting Information) consistent with published experimental studies performed with dune-like bedforms (Elliott \& Brooks, 1997; Marion et al., 2002; Packman et al., 2000b, 2004; Packman \& MacKay, 2003; Rehg et al., 2005; Ren \& Packman, 2004).

The volumetric water flux predicted by equation (2) varies sinusoidally with horizontal distance along the SWI, forming well-defined upwelling and downwelling regions that are fully characterized by a repeating unit cell, one of which occurs over the domain, $x^{*} \in[-\pi, \pi]$ (see figure 1b in Grant et al. (2020)). Thus, the RTD associated with Packman et al.'s hyporheic exchange flow field can be fully characterized by tracking the arrival times of particles released in the downwelling zone of a single unit cell. Accordingly, we released 10000 particles in the downwelling zone $\left(0 \leq x^{*} \leq \frac{\pi}{2}\right)$ of the unit cell centered on $x^{*}=0$, with a flux weighting scheme that added particles in proportion to the local downwelling flux (to assure that roughly the same number of particles entered the hyporheic zone along every streamline). The RTD for different choices of $d_{b}^{*}$ in Packman et al.'s flow model was obtained by fixing the length of each particle step within the sediment domain $\left(s^{*}=k s\right)$ to be $5 * 10^{-3}$. Then, the $i$-th time step $\left(t^{*}\right)$ was calculated as:

$t_{i}^{*}=\frac{s^{*}}{\sqrt{u_{i}^{* 2}+v_{i}^{* 2}}}$

where $u_{i}^{*}$ and $v_{i}^{*}$ denote the velocity components at the particle location at the end of $i$-th step. For each particle the time at the end of the $i$-th step $\left(t_{i}^{*}\right)$ within the sediment bed domain $\left(y^{*}<0\right)$ is:

$t_{i}^{*}=t_{i-1}^{*}+t_{i}^{*}, \quad i=1, \ldots, N,(13)$

where $t_{0}^{*}=0, \mathrm{~N}$ is the number of steps undertaken by each particle and the corresponding horizontal and vertical particle displacements $\left(x_{i}^{*}\right.$ and $y_{i}^{*}$, respectively) of the $i$-th step are:

$x_{i}^{*}=u_{i}^{*} \underline{t_{i}^{*}}(14)$

$y_{i}^{*}=v_{i}^{*} \underline{t_{i}^{*}}(15)$

where is the sediment effective porosity. For each $d_{b}^{*}$,cumulative distribution function (CDF) and probability density function (PDF) forms of the RTD were calculated from the observed residence times of the 10000 particles.

\subsection{Analytical Distribution Parameter Inference.}


Separate particle tracking RTDs were generated for 125 dimensionless bed depths ranging from $d_{b}^{*}=0.1$ to 20. Each of these RTDs was fit to the four analytical distributions (EXP, GAM , LN, and FR, see Table 1) described earlier using Maximum Likelihood Estimation (Mathematica, Wolfram). EXP is characterized by a decreasing monotonic function and parametrized by a single parameter $(\rho)$. The parameters for the GAM distribution, $\alpha$ and $\beta$, control the shape and scale characteristics of the distribution, respectively. The parameters of LN, $\mu$ and $\sigma$, determine the mean of the log-transformed random variable and its standard deviation, respectively. The FR distribution is a three-parameter distribution (shape parameter $s$, scale parameter $q$, and location parameterm), but for the sake of parsimony and for consistency with the other distributions considered in this study, the FR distribution with two parameters was chosen by fixing $s=1$, as assumed by Grant et al. (2020). To determine which of these distributions best represents the empirical RTD at each dimensionless depth $d_{b}^{*}$, the candidate analytical distributions were ranked using the KolmogorovSmirnov (KS) test, which measures the difference in the CDF between the particle tracking RTD and the assumed distribution:

$$
K S=\sup _{t}\left|\hat{F}\left(t^{*}\right)-F\left(t^{*}\right)\right|
$$

Where $\sup _{t}$ is the supremum over $t, \hat{F}\left(t^{*}\right)$ is the CDF form of the empirical RTD for a certain $d_{b}^{*}$, and $F\left(t^{*}\right)$ is the CDF form of the candidate analytical distribution. A set of regression formulae for each distribution was then prepared to correlate the analytical distribution parameters with $d_{b}^{*}$, using the "Curve Fitting" tool in Matlab.

[Insert Table 1]

\subsection{Application of analytical representations on predicting $\mathrm{N}$-cycling.}

Hyporheic zone denitrification ranges between 1-200\% of denitrification in the stream water column (Harvey et al., 2013). The Denitrification in streambed sediments depends on the presence of nitrate, labile organic carbon, and anaerobic zones within the sediment bed (Gomez-Velez et al., 2015; Zarnetske et al., 2012). In the downwelling zone, the movement of oxygen rich water from the stream into the sediments favors aerobic conditions which are generally (with the exception of anaerobic microzones (e.g., Zarnetske et al., 2011, 2012) unfavorable to denitrification (Azizian et al., 2015). As water parcels continue their journey through the hyporheic zone (i.e., at relatively long $t^{*}$ ) heterotrophic respiration of organic matter (associated with in-sediment microbial biofilms) leads to a progressive depletion of oxygen and an eventual shift to nitrate reducing (i.e., denitrifying) conditions (Azizian et al., 2015; Harvey et al., 2013; Zarnetske et al., 2011, 2015).

The boundary between aerobic and anaerobic zones is delineated by the Damköhler number for aerobic respiration $\left(\mathrm{Da}_{\mathrm{rp}}\right)$ (Zarnetske et al., 2012). It is defined as the ratio between the median residence time of all flow paths $\left(t_{50}\right)$ and the characteristic time necessary for oxygen consumption $\left(\tau_{\mathrm{rp}} \sim 1 \mathrm{~h}\right.$; Gomez et al., 2012; Gomez-Velez et al., 2015; Zarnetske et al., 2011). At $\mathrm{Da}_{\mathrm{rp}}<1$, aerobic conditions are dominant and denitrification is inhibited, while atDa $\mathrm{rp}_{\mathrm{rp}}>>1$ anaerobic conditions prevail and denitrification is likely (i.e., provided that the other two requirements, the presence of nitrate and labile organic matter, is satisfied) (Zarnetske et al., 2012). When flow paths exhibit residence times longer than a characteristic denitrification timescale $\left(\tau_{\mathrm{dn}} \sim 10 \mathrm{~h}\right.$; Gomez-Velez et al., 2015; Harvey et al., 2013; Zarnetske et al., 2015), they tend to be fully anaerobic, and all or most of the nitrate is removed $\left(\operatorname{Da}_{\mathrm{dn}}>>1\right)$. Correctly representing the residence time scales in the hyporheic zone, and therefore the Damköhler Numbers for aerobic respiration and denitrification, can lead to more accurate assessments of the link between the hyporheic zone RTD and key ecological functions, such as stream metabolism, generally, and denitrification, in particular (Mulholland et al., 2009).

The hydraulic and morphological properties of the Embarras River (Table 2) located $15 \mathrm{~km}$ south of UrbanaChampaign, east-central Illinois, USA (Sukhodolov et al., 2006) was considered in this study to demonstrate how the analytical framework introduced in this paper can be applied for predicting Da. This river was chosen due to the existence of a dunes-like bedform as its predominant morphology. 
[Insert Table 2]

\section{RESULTS AND DISCUSSIONS}

\subsection{Influence of Streambed Depth on the Empirical RTD}

The hyporheic zone RTDs generated by the particle tracking algorithm (empirical RTDs, see Methods) become progressively heavy tailed as the dimensionless depth is increased systematically from $d_{b}^{*}=0.5$ to 8 (Figure $1 A$ ). For dimensionless depths greater than, $d_{b}^{*}>6.2$, the shape of the empirical RTD converges to that for an infinitely deep bed (see variations in RTD quantiles in Figure $1 B$ ), consistent with the depth threshold reported by Wörman et al. (2002) of $\frac{d_{b}}{\lambda}=1$ (equivalent to $d_{b}^{*}=2 \pi$ ).

[Insert Figure 1]

\subsection{Analytical Representations of the Empirical RTD.}

Because the RTD becomes progressively heavy tailed with increasing streambed depth, no single analytical distribution represents the RTD over the full range of $d_{b}^{*}$ tested here (Table S1, Supplemental Material). Instead, the RTD is best approximated by different analytical distributions over different depth ranges, including: (1) GAM for shallow streambeds $\left(0 \leq d_{b}^{*} \leq 1.2\right.$, Figure 2); (2) LN for streambeds of intermediate depth $\left(1.2<d_{b}^{*} \leq 3.1\right.$, Figure 3$)$; and (3) FR for deep streambeds $\left(d_{b}^{*}>3.1\right.$, Figure 4$)$. Contrary to previous reports (e.g., Zaramella et al., 2003), the EXP distribution appears to be a poor representation of the empirical RTD across all streambed depths tested in this study. LN has been recommended as a surrogate for the hyporheic zone RTD in many studies (e.g., Cardenas et al., 2008; Alessandra Marzadri et al., 2016). Our results demonstrate that LN is a good representation for an intermediate range of $d_{b}^{*}$, consistent with Wörman et al. (2002) who reported that the RTD is well fit by LN at $\frac{d_{b}}{\lambda}=0.25$.

[Insert Figures 2 and 3]

For deep beds $d_{b}^{*}(>3.1)$, FR appears to be the best representation distribution of the empirical RTDs, consistent with Grant et al. (2020) who found that FR was a close approximation of the RTD predicted by the bedform pumping model in a quasi-infinite streambed (Figure 2 in their paper).

[Insert Figure 4]

\subsection{Predicting the distribution parameters.}

The parameters values fitted for each distribution are a function of $d_{b}^{*}$ (Figure 5). For the GAM, $\alpha$ decreases and $\beta$ increases with higher $d_{b}^{*}$ (Figure $5 \mathrm{~A}$ ) as the distribution shape shifts from unimodal to monotonically decreasing for $d_{b}^{*}>\sim 3$. For $\mathrm{LN}$, both $\mu$ and $\sigma$ increase with $d_{b}^{*}$ as the thickness of the tail increases to describe longer $t^{*}$ at higher $d_{b}^{*}$ values (Figure 5B). For FR, $\beta$ increases and $\mu$ decreases (Figure 5C), as the distribution flattens and its peak shifts towards longer $t^{*}$ and, lastly, for EXP, $\rho$ decreases with $d_{b}^{*}$. For all distributions, the parameters attain constant values for high $d_{b}^{*}$, reflecting the convergence to the RTD for a quasi-infinite streambed. The regression formula for each of these parameters (Table 3) capture a very large fraction of the variance in the parameter values with dimensionless depth $\left(R^{2} \geq 99.8 \%\right.$ with small Root Mean Square Error in all cases). These formulae are applicable over the whole range $d_{b}^{*}$ considered in this study (from very shallow to quasi-infinite $d_{b}^{*}$ ), and hence provide a useful tool for future modelling studies.

\section{[Insert Table 3]}

[Insert Figure 5]

\subsection{Analytical RTD Predictions of the Damköhler number.}

The previously published properties of the Embarras River (Sukhodolov et al., 2006) were used to normalize the residence times $\left(\tau_{\mathrm{rp}} \sim 1 \mathrm{~h}\right.$ and $\tau_{\mathrm{dn}} \sim 10 \mathrm{~h}$, respectively) using eq. 11 . Then, for different $d_{b}^{*}$, the empirical $\mathrm{Da}_{\mathrm{rp}}$ and $\mathrm{Da}_{\mathrm{dn}}$ were calculated as the ratio between the empirical $t_{50}$ and the normalized respiration and the denitrification time $\operatorname{scales} \tau_{\mathrm{rp}}^{*}$ and $\tau_{\mathrm{dn}}^{*}$, of $\sim 1 \mathrm{~h}$ and $\sim 10 \mathrm{~h}$ respectively. The correspondingDa $\mathrm{rp}$ and $\mathrm{Da}_{\mathrm{dn}}$ were calculated for each of our four analytical representations of the hyporheic zone RTD (GAM, LN, 
FR, EXP), and then compared to the Da values estimated from the empirical RTD (which was assumed here to be the gold standard) (Figure 6). It should be noticed thatDa $a_{\mathrm{rp}}$ and $\mathrm{Da}_{\mathrm{dn}}$ are simply proportional to each other (because they differ only by the reaction timescale), so the comparison between empirical and analytical representations of Da does not depend on the specific reaction considered.

Damkhöler Numbers generated from the empirical RTD (asterisks in Figure 6) decline more-or-less monotonically with increasing dimensionless streambed depth. This pattern is best represented by GAM for $d_{b}^{*}<1.2$, and by FR over the full range of $d_{b}^{*}$ evaluated here. The LN and EXP distributions under- and over-estimate the Da for dimensionless depths $d_{b}^{*}<1.0$ and $d_{b}^{*}>1.0$, respectively. This result-that FR provides the best estimate of the Damkohler Number over the two-order of magnitude change in dimensionless sediment bed depth evaluated here - is surprising given that this analytical distribution is not the best representation of the empirical RTD for $d_{b}^{*}<3.1$ (see above). The explanation is that, even for shallow depths, the optimized FR CDF intersects the empirical CDF at a cumulative probability of 0.5 across all dimensionless depth ranges evaluated here (compare green curve and asterisks, left panels, Figures 2-6). Hence, the analytical distribution's estimate for $t_{50}$ (and hence the Damköhler Number) is accurate, even for shallow bed depths where FR is a relatively poor representation of the empirical RTD.

[Insert Figure 6]

\section{CONCLUSIONS}

The hyporheic zone RTD associated with bedform pumping across dunes is well represented by one or more analytical distributions, depending on the dimensionless streambed depth. From Kolmogorov-Smirnov ranking of the distributions we find that the empirical RTD is well represented by a Gamma distribution for shallow streambeds $\left(d_{b}^{*} \leq 1.2\right)$, a Log Normal distribution for intermediate streambed depths $\left(1.2<d_{b}^{*} \leq\right.$ $3.1)$; and the Fréchet distribution for very deep streambeds $\left(d_{b}^{*}>3.1\right)$. Values of the distribution parameters are a function of the dimensionless streambed $\operatorname{depth} d_{b}^{*}$, and can be predicted to a high degree of accuracy using simple regression formulae. The results presented in this study should prove useful for modelling hyporheic exchange and assessing nutrient processing in the hyporheic zone. Even though the FR cannot capture the whole shape of the RTD in shallow beds, it still accurately represents the median residence time, $t_{50}$. Therefore, the optimized FR distribution is best able to represent Damköhler Numbers estimated from the empirical RTD over the $>2$ order of magnitude range of streambed depths evaluated in this study.

\section{ACKNOWLEDGEMENTS}

Funding was provided by Compagnia San Paolo through the Joint Research Projects Initiative (entitled "River network self-depuration") and a U.S. National Science Foundation (NSF) research grant to SBG (NSF Award \#2021015).

\section{REFERENCES}

Azizian, M., Boano, F., Cook, P. L., Detwiler, R. L., Rippy, M. A., \& Grant, S. B. (2017). Ambient groundwater flow diminishes nitrate processing in the hyporheic zone of streams. Water Resources Research, 53 (5), 3941-3967.

Azizian, M., Grant, S. B., Kessler, A. J., Cook, P. L., Rippy, M. A., \& Stewardson, M. J. (2015). Bedforms as biocatalytic filters: A pumping and streamline segregation model for nitrate removal in permeable sediments. Environmental Science 83 Technology , 49 (18), 10993-11002.

Baxter, C. V., \& Hauer, F. R. (2000). Geomorphology, hyporheic exchange, and selection of spawning habitat by bull trout (Salvelinus confluentus). Canadian Journal of Fisheries and Aquatic Sciences ,57 (7), 14701481.

Beaulieu, J. J., Tank, J. L., Hamilton, S. K., Wollheim, W. M., Hall, R. O., Mulholland, P. J., Peterson, B. J., Ashkenas, L. R., Cooper, L. W., Dahm, C. N., \& others. (2011). Nitrous oxide emission from denitrification in stream and river networks. Proceedings of the National Academy of Sciences , 108 (1), 214-219. 
Bencala, K. E. (1983). Simulation of solute transport in a mountain pool-and-riffle stream with a kinetic mass transfer model for sorption. Water Resources Research , 19 (3), 732-738.

Boano, F., Packman, A., Cortis, A., Revelli, R., \& Ridolfi, L. (2007). A continuous time random walk approach to the stream transport of solutes. Water Resources Research , 43 (10).

Bottacin-Busolin, A., \& Marion, A. (2010). Combined role of advective pumping and mechanical dispersion on time scales of bed form-induced hyporheic exchange. Water Resources Research , 46 (8).

Cardenas, M. B., Wilson, J. L., \& Haggerty, R. (2008). Residence time of bedform-driven hyporheic exchange. Advances in Water Resources , 31 (10), 1382-1386.

Elliott, A. H., \& Brooks, N. H. (1997). Transfer of nonsorbing solutes to a streambed with bed forms: Laboratory experiments. Water Resources Research, 33 (1), 137-151.

Feminella, J. W., \& Walsh, C. J. (2005). Urbanization and stream ecology: An introduction to the series. Journal of the North American Benthological Society , 24 (3), 585-587.

Fox, A., Boano, F., \& Arnon, S. (2014). Impact of losing and gaining streamflow conditions on hyporheic exchange fluxes induced by dune-shaped bed forms. Water Resources Research , 50 (3), 1895-1907.

Frei, S., Azizian, M., Grant, S. B., Zlotnik, V. A., \& Toundykov, D. (2019). Analytical modeling of hyporheic flow for in-stream bedforms: Perturbation method and implementation. Environmental Modelling 83 Software , 111, 375-385.

Galloway, J., Fox, A., Lewandowski, J., \& Arnon, S. (2019). The effect of unsteady streamflow and streamgroundwater interactions on oxygen consumption in a sandy streambed. Scientific Reports ,9 (1), 1-11.

Gomez, J. D., Wilson, J. L., \& Cardenas, M. B. (2012). Residence time distributions in sinuosity-driven hyporheic zones and their biogeochemical effects. Water Resources Research , 48 (9).

Gomez-Velez, J. D., Harvey, J. W., Cardenas, M. B., \& Kiel, B. (2015). Denitrification in the Mississippi River network controlled by flow through river bedforms. Nature Geoscience , 8 (12), 941-945.

Gomez-Velez, J. D., Krause, S., \& Wilson, J. L. (2014). Effect of low-permeability layers on spatial patterns of hyporheic exchange and groundwater upwelling. Water Resources Research , 50 (6), 5196-5215.

Grant, S. B., Gomez-Velez, J. D., \& Ghisalberti, M. (2018). Modeling the effects of turbulence on hyporheic exchange and local-to-global nutrient processing in streams. Water Resources Research ,54 (9), 5883-5889.

Grant, S. B., Litton-Mueller, R. M., \& Ahn, J. H. (2011). Measuring and modeling the flux of fecal bacteria across the sediment-water interface in a turbulent stream. Water Resources Research , 47 (5).

Grant, S. B., Monofy, A., Boano, F., Gomez-Velez, J. D., Guymer, I., Harvey, J., \& Ghisalberti, M. (2020). Unifying advective and diffusive descriptions of bedform pumping in the benthic biolayer of streams. Water Resources Research , 56 (11), e2020WR027967.

Grant, S. B., Stolzenbach, K., Azizian, M., Stewardson, M. J., Boano, F., \& Bardini, L. (2014). First-order contaminant removal in the hyporheic zone of streams: Physical insights from a simple analytical model. Environmental Science 83 Technology , 48 (19), 11369-11378.

Harvey, J., \& Gooseff, M. (2015). River corridor science: Hydrologic exchange and ecological consequences from bedforms to basins. Water Resources Research , 51 (9), 6893-6922.

Harvey, J. W., Böhlke, J. K., Voytek, M. A., Scott, D., \& Tobias, C. R. (2013). Hyporheic zone denitrification: Controls on effective reaction depth and contribution to whole-stream mass balance. Water Resources Research , 49 (10), 6298-6316.

Kirchner, J. W., Feng, X., \& Neal, C. (2000). Fractal stream chemistry and its implications for contaminant transport in catchments. Nature , 403 (6769), 524-527. 
Knapp, J. L., \& Kelleher, C. (2020). A perspective on the future of transient storage modeling: Let's stop chasing our tails. Water Resources Research , 56 (3), e2019WR026257.

Marion, A., Bellinello, M., Guymer, I., \& Packman, A. (2002). Effect of bed form geometry on the penetration of nonreactive solutes into a streambed. Water Resources Research , 38 (10), 27-1.

Marzadri, A., Dee, M. M., Tonina, D., Bellin, A., \& Tank, J. L. (2017). Role of surface and subsurface processes in scaling $\mathrm{N} 2 \mathrm{O}$ emissions along riverine networks. Proceedings of the National Academy of Sciences , 114 (17), 4330-4335.

Marzadri, A., Tonina, D., Bellin, A., \& Tank, J. (2014). A hydrologic model demonstrates nitrous oxide emissions depend on streambed morphology. Geophysical Research Letters , 41 (15), 5484-5491.

Marzadri, A., Tonina, D., Bellin, A., \& Valli, A. (2016). Mixing interfaces, fluxes, residence times and redox conditions of the hyporheic zones induced by dune-like bedforms and ambient groundwater flow. Advances in Water Resources , 88, 139-151.

Morén, I., Wörman, A., \& Riml, J. (2017). Design of remediation actions for nutrient mitigation in the hyporheic zone. Water Resources Research, 53 (11), 8872-8899.

Mulholland, P. J., Hall, R. O., Sobota, D. J., Dodds, W. K., Findlay, S. E. G., Grimm, N. B., Hamilton, S. K., McDowell, W. H., O’Brien, J. M., Tank, J. L., Ashkenas, L. R., Cooper, L. W., Dahm, C. N., Gregory, S. V., Johnson, S. L., Meyer, J. L., Peterson, B. J., Poole, G. C., Valett, H. M., ... Thomasn, S. M. (2009). Nitrate removal in stream ecosystems measured by $15 \mathrm{~N}$ addition experiments: Denitrification.Limnology and Oceanography , 54 (3), 666-680. https://doi.org/10.4319/lo.2009.54.3.0666

Packman, A. I., Brooks, N. H., \& Morgan, J. J. (2000a). A physicochemical model for colloid exchange between a stream and a sand streambed with bed forms. Water Resources Research , 36 (8), 2351-2361.

Packman, A. I., Brooks, N. H., \& Morgan, J. J. (2000b). Kaolinite exchange between a stream and streambed: Laboratory experiments and validation of a colloid transport model. Water Resources Research , 36 (8), 2363-2372.

Packman, A. I., \& MacKay, J. S. (2003). Interplay of stream-subsurface exchange, clay particle deposition, and streambed evolution. Water Resources Research, 39 (4).

Packman, A. I., Salehin, M., \& Zaramella, M. (2004). Hyporheic exchange with gravel beds: Basic hydrodynamic interactions and bedform-induced advective flows. Journal of Hydraulic Engineering , 130 (7), $647-656$.

Rehg, K. J., Packman, A. I., \& Ren, J. (2005). Effects of suspended sediment characteristics and bed sediment transport on streambed clogging. Hydrological Processes: An International Journal ,19 (2), 413-427.

Ren, J., \& Packman, A. I. (2004). Stream-subsurface exchange of zinc in the presence of silica and kaolinite colloids. Environmental Science 83 Technology , 38 (24), 6571-6581.

Runkel, R. L. (1998). One-dimensional transport with inflow and storage (OTIS): A solute transport model for streams and rivers (Vol. 98). US Department of the Interior, US Geological Survey.

Sawyer, A. H., Bayani Cardenas, M., \& Buttles, J. (2012). Hyporheic temperature dynamics and heat exchange near channel-spanning logs. Water Resources Research , 48 (1).

Stewardson, M., Datry, T., Lamouroux, N., Pella, H., Thommeret, N., Valette, L., \& Grant, S. (2016). Variation in reach-scale hydraulic conductivity of streambeds. Geomorphology , 259 , 70-80.

Sukhodolov, A. N., Fedele, J. J., \& Rhoads, B. L. (2006). Structure of flow over alluvial bedforms: An experiment on linking field and laboratory methods. Earth Surface Processes and Landforms: The Journal of the British Geomorphological Research Group , 31 (10), 1292-1310. 
Tonina, D., de Barros, F. P., Marzadri, A., \& Bellin, A. (2016). Does streambed heterogeneity matter for hyporheic residence time distribution in sand-bedded streams? Advances in Water Resources , 96 , 120-126.

Tonina, D., Marzadri, A., \& Bellin, A. (2015). Benthic uptake rate due to hyporheic exchange: The effects of streambed morphology for constant and sinusoidally varying nutrient loads. Water , 7 (2), 398-419.

Tóth, J. (1962). A theory of groundwater motion in small drainage basins in central Alberta, Canada. Journal of Geophysical Research ,67 (11), 4375-4388.

Urumović, K., \& Urumović Sr, K. (2014). The effective porosity and grain size relations in permeability functions. Hydrology and Earth System Sciences Discussions , 11 (6), 6675-6714.

Vaux, W. G. (1968). Intragravel flow and interchange of water in a streambed. Fishery Bulletin of the Fish and Wildlife Service, 66 (3), 479-489.

White, D. S., Elzinga, C. H., \& Hendricks, S. P. (1987). Temperature patterns within the hyporheic zone of a northern Michigan river.Journal of the North American Benthological Society , 6 (2), 85-91.

Wörman, A., Packman, A. I., Johansson, H., \& Jonsson, K. (2002). Effect of flow-induced exchange in hyporheic zones on longitudinal transport of solutes in streams and rivers. Water Resources Research, 38 (1), $2-1$.

Wu, F.-C. (2000). Modeling embryo survival affected by sediment deposition into salmonid spawning gravels: Application to flushing flow prescriptions. Water Resources Research , 36 (6), 1595-1603.

Zaramella, M., Packman, A. I., \& Marion, A. (2003). Application of the transient storage model to analyze advective hyporheic exchange with deep and shallow sediment beds. Water Resources Research ,39 (7).

Zarnetske, J. P., Haggerty, R., \& Wondzell, S. M. (2015). Coupling multiscale observations to evaluate hyporheic nitrate removal at the reach scale. Freshwater Science , 34 (1), 172-186.

Zarnetske, J. P., Haggerty, R., Wondzell, S. M., \& Baker, M. A. (2011). Dynamics of nitrate production and removal as a function of residence time in the hyporheic zone. Journal of Geophysical Research: Biogeosciences , 116 (G1).

Zarnetske, J. P., Haggerty, R., Wondzell, S. M., Bokil, V. A., \& González-Pinzón, R. (2012). Coupled transport and reaction kinetics control the nitrate source-sink function of hyporheic zones. Water Resources Research , 48 (11).

\section{TABLES}

Table 1: A list of the adopted analytical distributions in this study with their associated pdf formulae and parameters.

Table 2: Embarras River properties used for normalizing the respiration and denitrification time scales. + Porosity was obtained from Figure 5 in Urumović and Urumović Sr (2014) by considering the referential grain size $=D_{m} .++$ The hydraulic conductivity was calculated with the Kozeny-Carman equation.

Table 3: Regression formulae to predict the values of the distribution parameters as a function of the value of the relative sediment depth $\left(d_{b}^{*}\right)$.

\section{FIGURE LEGENDS}

Figure 1: A) Variations in empirical pdf of the log transferred residence times for different relative sediment depth $\left(d_{b}^{*}\right)$ values. B) the change in empirical RTD quantiles $(10 \%, 50 \%$, and $90 \%)$ versus $d_{b}^{*}$ values.

Figure 2: Empirical CDF (A) and pdf (B) produced for a shallow relative sediment depth $\left(d_{b}^{*}=0.5\right)$ fitted to different CDFs and pdfs of the selected analytical distributions. The best-fitting analytical distribution (GAM) is found using the Kolmogorov-Smirnov test. 
Figure 3: Empirical CDF (A) and pdf (B) produced for a shallow relative sediment depth $\left(d_{b}^{*}=1.5\right)$ fitted to different CDFs and pdfs of the selected distributions. The best-fitting analytical distribution (LN) is found using the Kolmogorov-Smirnov test.

Figure 4: Empirical CDF (A) and pdf (B) produced for a shallow relative sediment depth $\left(d_{b}^{*}=8\right)$ fitted to different CDFs and pdfs of the selected distributions. The best-fitting analytical distribution (FR) is found using the Kolmogorov-Smirnov test.

Figure 5: Values of distributions parameters (Gamma (A), Log-Normal (B), Fréchet (C), and Exponential (D)) as a function of the relative sediment depth $\left(d_{b}^{*}\right)$. The estimated parameters (markers) are found using a Kolmogorov-Smirnov test and predicted values (lines) are calculated with the formulae in Table 2.

Figure 6: Comparison between the Damköhler number of respiration and denitrification $\left(\mathrm{Da}_{\mathrm{rp}} \mathrm{and}_{\mathrm{Da} \mathrm{dn}}\right.$, respectively) calculated at different $d_{b}^{*}$ from the empirical RTD $\left(\mathrm{Da}_{\mathrm{Emp}}\right)$, and the ones calculated by different analytical representations $\left(\mathrm{Da}_{\mathrm{GAM}}, \mathrm{Da}_{\mathrm{LN}}, \mathrm{Da}_{\mathrm{FR}}\right.$, andDa $\left.\mathrm{ExP}\right)$.
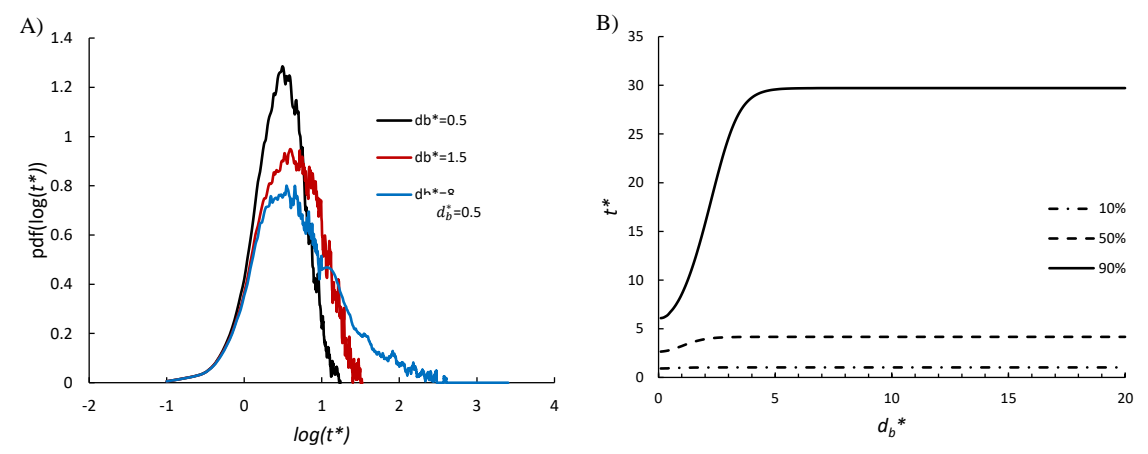

Figure 1: A) Variations in empirical pdf of the log transferred residence times for different relative sediment depth $\left(d_{b}^{*}\right)$ values. B) the change in empirical RTD quantiles $(10 \%, 50 \%$, and $90 \%)$ versus $d_{b}^{*}$ values.
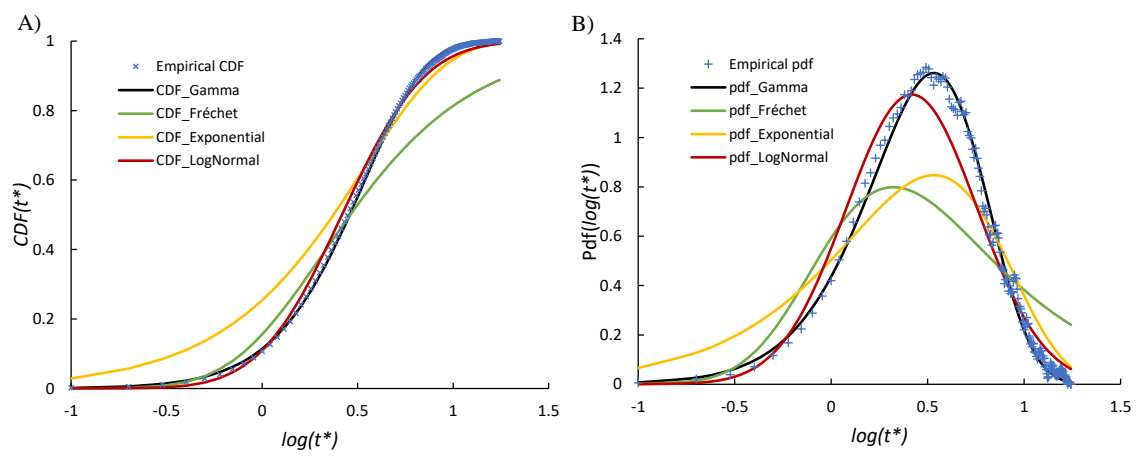

Figure 2: Empirical CDF (A) and pdf (B) produced for a shallow relative sediment depth $\left(d_{b}^{*}=0.5\right)$ fitted to different $\mathrm{CDFs}$ and pdfs of the selected analytical distributions. The best-fitting analytical distribution (GAM) is found using the Kolmogorov-Smirnov test. 

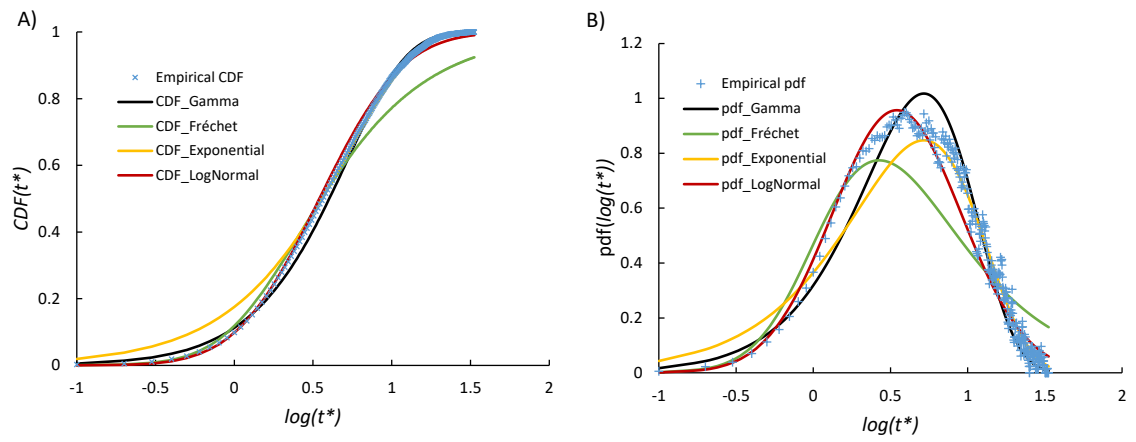

Figure 3: Empirical CDF (A) and pdf (B) produced for a shallow relative sediment depth $\left(d_{b}^{*}=1.5\right)$ fitted to different CDFs and pdfs of the selected distributions. The best-fitting analytical distribution (LN) is found using the Kolmogorov-Smirnov test.
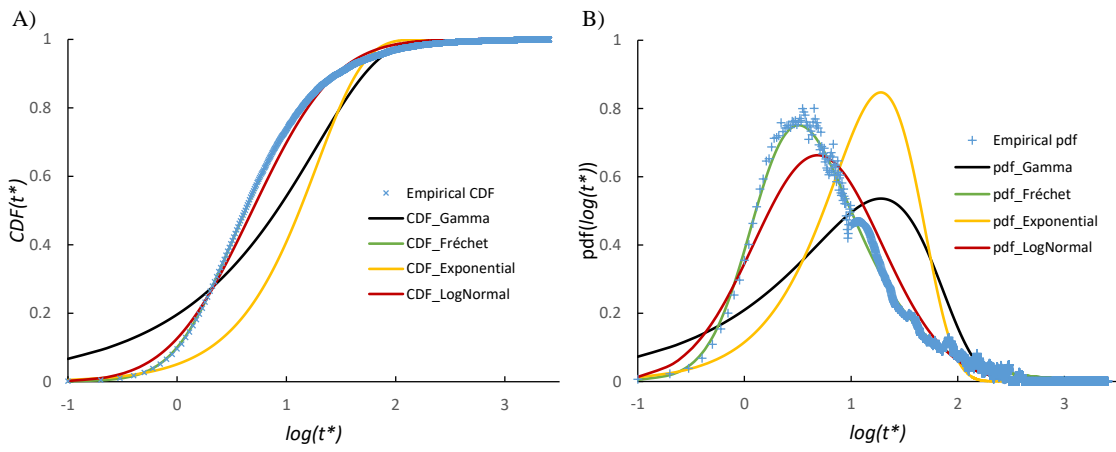

Figure 4: Empirical CDF (A) and pdf (B) produced for a shallow relative sediment depth $\left(d_{b}^{*}=8\right)$ fitted to different CDFs and pdfs of the selected distributions. The best-fitting analytical distribution (FR) is found using the Kolmogorov-Smirnov test.
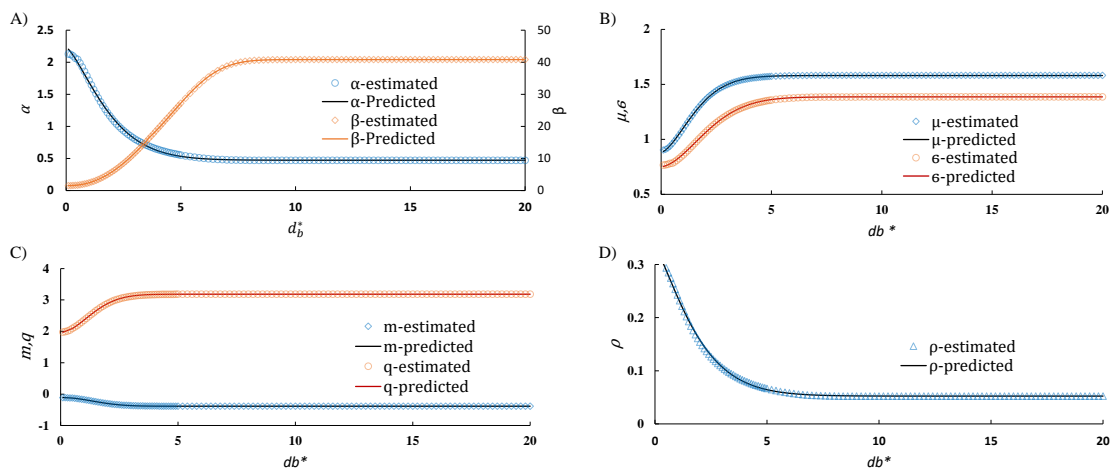

Figure 5: Values of distributions parameters (Gamma (A), Log-Normal (B), Fréchet (C), and Exponential (D)) as a function of the relative sediment depth $\left(d_{\dot{b}}^{*}\right)$. The estimated parameters (markers) are found using a Kolmogorov-Smirnov test and predicted values (lines) are calculated with the formulae in Table 2. 


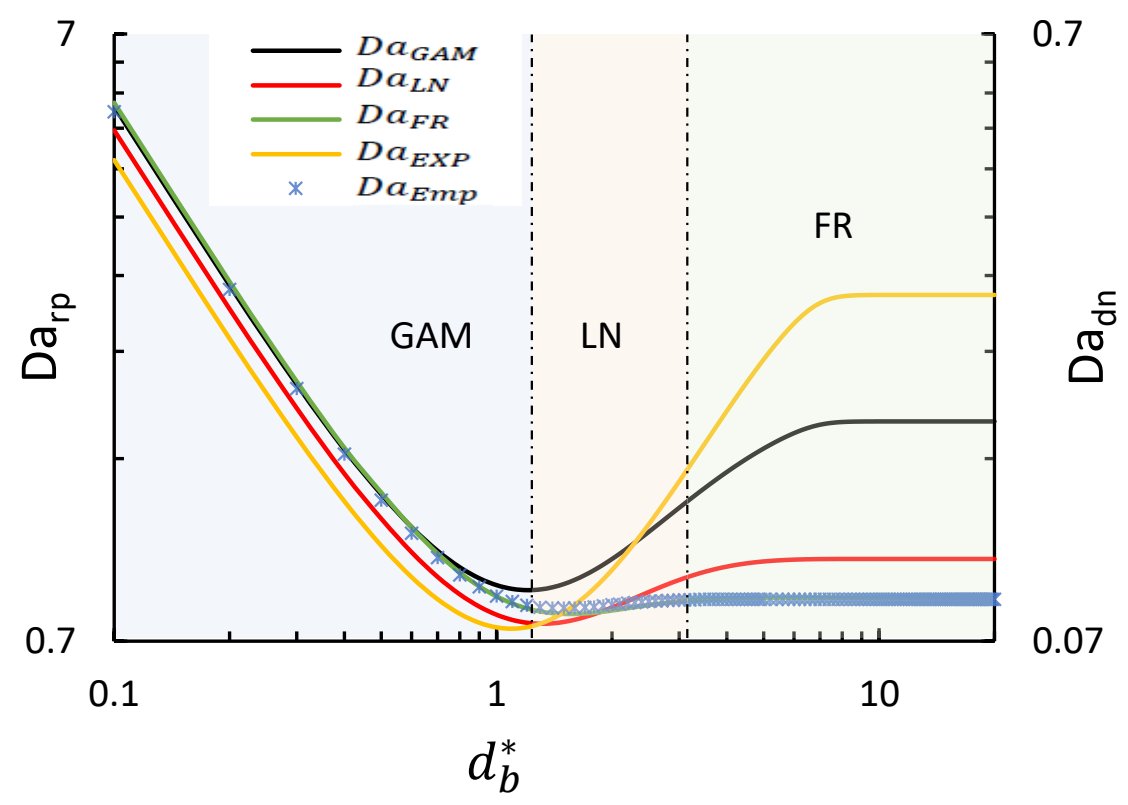

Figure 6: Comparison between the Damköhler number of respiration and denitrification ( $D a_{r p}$ and $D a_{d n}$, respectively) calculated at different $d_{b}^{*}$ from the empirical RTD ( $\left.D a_{E m p}\right)$, and the ones calculated by different analytical representations ( $D a_{G A M}, D a_{L N}, D a_{F R}$, and $\left.D a_{E X P}\right)$. 
Table 1: A list of the adopted analytical distributions in this study with their associated pdf formulae and parameters.

\begin{tabular}{|l|c|c|}
\hline Distribution & pdf & parameters \\
\hline Gamma & $\frac{e^{-\frac{t^{*}}{\beta} t^{*-1+\alpha} \beta^{-\alpha}}}{\operatorname{Gamma}[\alpha]} t^{*}>0$ & $\alpha, \beta$ \\
\hline Log-Normal & $\frac{e^{-\frac{\left(-\mu+\log \left[t^{*}\right]\right)^{2}}{2 \sigma^{2}}}}{\sqrt{2 \pi} t^{*} \sigma} t^{*}>0$ & $\mu, \sigma$ \\
\hline Fréchet & $\frac{e^{-\frac{q}{t^{*}-m} q}}{\left(t^{*}-m\right)^{2}} t^{*}>m$ & $s=1, q, m$ \\
\hline Exponential & $\rho e^{-t^{*} \rho} t^{*} \geq 0$ & $\rho$ \\
\hline
\end{tabular}


Table 2: Embarras River properties used for normalizing the respiration and denitrification time scales. † Porosity was obtained from Figure 5 in Urumović and Urumović Sr (2014) by considering the referential grain size $=D_{m} . \ddagger$ The hydraulic conductivity was calculated with the Kozeny-Carman equation.

\begin{tabular}{|l|c|}
\hline \multicolumn{2}{|c|}{ Embarras River Properties } \\
\hline mean grain size $\left(D_{m}\right)$ & $1 \mathrm{~mm}$ \\
\hline stream depth $(d)$ & $0.35 \mathrm{~m}$ \\
\hline mean stream Velocity $\left(U_{\text {mean }}\right)$ & $0.44 \mathrm{~m} / \mathrm{s}$ \\
\hline Dune wavelength $(\lambda)$ & $1 \mathrm{~m}$ \\
\hline Dune height $(H)$ & $0.1 \mathrm{~m}$ \\
\hline Dune roughness $(H / d)$ & 0.29 \\
\hline Porosity $(\theta) \dagger$ & 0.32 \\
\hline Hydraulic conductivity $\left(K_{c}\right) \ddagger$ & $4.4 E$ \\
& $-3 \mathrm{~m} / \mathrm{s}$ \\
\hline
\end{tabular}


Table 3: Regression formulae to predict the values of the distribution parameters as a function of the value of the relative sediment depth $\left(d_{b}^{*}\right)$.

\begin{tabular}{|c|c|c|c|}
\hline Distribution & Formulae & $R^{2}$ & RMSE \\
\hline $\operatorname{Gamma}[\alpha, \beta]$ & $\begin{array}{l}\alpha=(0.47 \pm 0.002)+(1.76 \pm 0.01) e^{(-0.37 \pm 0.007) d_{b}^{*(1.37 \pm 0.02)}} \\
\beta= \\
\begin{cases}(48.4 \pm 0.46)+(-46.91 \pm 0.46) e^{(-0.02 \pm 2 E-4) d_{b}^{*(2.31 \pm 0.003)}} & d_{b}^{*} \leq 3.5 \\
(40.82 \pm 0.01)+(-32.81 \pm 0.19) e^{(-0.004 \pm 2 E-4) d_{b}^{*(3.36 \pm 0.02)}} & d_{b}^{*} \geq 3.5\end{cases} \end{array}$ & $\begin{array}{l}99.9 \% \\
99.9 \%\end{array}$ & $\begin{array}{l}0.017 \\
0.004 \\
0.065\end{array}$ \\
\hline $\operatorname{LogNormal}[\mu, \sigma]$ & $\begin{array}{l}\mu=(1.58 \pm 5 E-4)+(-0.7 \pm 0.002) e^{(-0.38 \pm 0.004) d_{b}^{*(1.58 \pm 0.009)}} \\
\sigma=(1.39 \pm 5 E-4)+(-0.63 \pm 0.001) e^{(-0.2 \pm 0.002) d_{b}^{*(1.74 \pm 0.009)}}\end{array}$ & $\begin{array}{l}99.9 \% \\
99.9 \%\end{array}$ & 0.003 \\
\hline Fréchet $[1, q, m]$ & $\begin{array}{l}q=(3.18 \pm 5 E-4)+(-1.22 \pm 0.002) e^{(-0.39 \pm 0.002) d_{b}^{*(1.84 \pm 0.005)}} \\
m=(-0.39 \pm 1 E-4)+(0.28 \pm 5 E-4) e^{(-0.28 \pm 0.002) d_{b}^{*(2.1 \pm 0.01)}}\end{array}$ & $\begin{array}{l}99.9 \% \\
99.9 \%\end{array}$ & 0.002 \\
\hline Exponential $[\rho]$ & $\boldsymbol{\rho}=(0.05 \pm 3 E-4)+(0.28 \pm 0.002) e^{(-0.4 \pm 0.006) d_{b}^{*(1.3 \pm 0.01)}}$ & $99.9 \%$ & 0.002 \\
\hline
\end{tabular}

